\title{
Conceptualização de órgãos sexuais e identidade de gêneros: tabu e preconceito
}

\author{
Sexual organs conceptualization and gender identity: \\ taboo and prejudice
}

\author{
Patrícia Oliveira de Freitas \\ Sandra Pereira Bernardo \\ Fernanda Carneiro Cavalcanti
}

Universidade do Estado do Rio de Janeiro (UERJ) - Brasil

\begin{abstract}
Resumo: Em pesquisa de mestrado (FREITAS, 2017), observaram-se os processos cognitivos que subjazem à construção de sentidos de piadas com emprego de nomes populares dados à vulva e ao pênis. Os dados, analisados fundamentalmente sob a ótica da Teoria da Metáfora Conceptual (LAKOFF; JOHNSON, 1980) e da Teoria da Integração Conceptual (FAUCONNIER; TURNER, 2002), demonstram depreciação nos nomes dados à vulva em oposição aos nomes dados ao pênis. Verificou-se, com base nesses dados, que o acionamento do conhecimento convencionalizado dos falantes relativo a determinadas partes do corpo perpassa pelo âmbito do tabu linguístico (ULLMANN, 1966; GUÉRIOS, 1979). Nesse sentido, existem formas de contornar a restrição vocabular, utilizando-se de comparações que se pautam, predominantemente, em relações vitais de REPRESENTAÇÃO e ANALOGIA (FAUCONNIER; TURNER, 2002). Além disso, constatou-se que, para contornar a restrição vocabular moralmente estabelecida, são ativadas metáforas conceptuais gerais. Pretende-se, com este trabalho, ilustrar a conceptualização dos nomes dados à vulva sob a perspectiva da construção da identidade de gênero, levando-se em consideração os valores culturais e experienciais subjacentes a essas metáforas do pensamento e, consequentemente, a tais designações de valor depreciativo.
\end{abstract}

Palavras-chave: Identidade de gênero. Metáfora. Órgãos sexuais. Preconceito. Tabuísmo.

Abstract: In a research realized for the masters degree (FREITAS, 2017), there were observed the cognitive processes that underlie the construction of senses of jokes with employment of popular names given to the vulva and to the penis. The data, analysed fundamentally under the lens of Conceptual Metaphor Theory (LAKOFF; JOHNSON, 1980) and Conceptual Integration Theory (FAUCONNIER; TURNER, 2002), demonstrated depreciation in the names given to the vulva in opposition to the names given to the penis. It was verified, based on these data, that the activation of the conventionalized knowledge of the speakers relative to certain parts of the body goes through the linguistic taboo (ULLMANN, 1966; GUÉRIOS, 1979). In this sense, there are ways to circumvent the vocabulary restriction, using comparisons that are predominantly based on vital relations of REPRESENTATION and ANALOGY (FAUCONNIER; TURNER, 2002). In addition, it has been found that, in order to circumvent the morally established vocabulary restriction, conceptual general metaphors are activated. It is intended, with this work, to instance the conceptualization of the names given to the vulva under the perspective of the gender construction, taking into consideration the cultural and experiential values underlying these metaphors of thought and consequently, to such designations of depreciatory value.

Keywords: Gender identity. Metaphor. Prejudice. Sexual Organs. Tabuism.

\section{Introdução}


Em pesquisa de mestrado (FREITAS, 2017), observaram-se os processos cognitivos subjacentes à construção de sentidos de piadas com emprego de nomes populares para vulva e pênis. A principal motivação para esse estudo sucedeu de listas disponíveis na internet que demonstram criatividade na atribuição de nomes aos referidos órgãos. Nessa pesquisa, partiu-se do princípio de que existem restrições de cunho moral que incorrem no uso do léxico relativo aos órgãos sexuais, uma vez que determinadas partes do corpo são objetos de tabu.

A respeito do objeto de tabu, afirma-se que a interdição vocabular se deve aos costumes comportamentais de uma sociedade, os quais suscitam uma transposição do que é conhecido como "bom/mau costume" para o campo lexical. Assim, a palavra que referencia elementos proibidos é igualmente interditada, sendo, também, um objeto atingido por tabu. Em consequência disso, as palavras passam a refletir a prática social, que julga quais vocábulos, em nome da ética, podem circular.

Nesse sentido, argumenta-se em defesa da ideia de que a mesclagem conceptual é o processo que permite a união de vários domínios cognitivos que revelam criatividade do pensamento, de modo a lidar com tabus, criando tanto eufemismos para contornar o significado quanto suscitando a aceitação social de vocábulos/objetos tabuizados. Além disso, quando acionado o frame relativo a ÓRGÃOS SEXUAIS, alguns desses processos cognitivos tendem a se repetir de forma relativamente estável, como, por exemplo, a ativação das relações vitais de REPRESENTAÇÃO e ANALOGIA (FAUCONNIER; TURNER, 2002), presentes nos dados analisados, que justificam as designações metonímicometafóricas, aventadas como formas de se evitar a palavra tabuizada.

Por meio de 42 testes interpretativos aplicados a universitários, observou-se a ativação recorrente das metáforas conceptuais gerais dos tipos PESSOA É OBJETO, (PARTE DO) CORPO HUMANO É OBJETO, PESSOA É ANIMAL, (PARTE DO) CORPO HUMANO É ANIMAL O (PARTE DO CORPO DA) PESSOA É PLANTA, que estruturam metáforas conceptuais mais específicas motivadas por aspectos socioculturais, tais como PÊNIS É OBJETO ERETO E RIJO, PÊNIS É OBJETO CILÍNDRICO E RETO, PÊNIS É AVE, VULVA É OBJETO CURVO, VULVA É MATAGAL e VULVA É RECEPTÁCULO DO PÊNIS.

Nesse contexto, parte-se do princípio de que essa jocosidade, evidenciada pelo processamento da mesclagem, muito embora atenue o tensionamento provocado pela visão preconceituosa em relação à condição feminina, o reafirma de maneira inusitada. Em outras palavras, as habilidades imaginativas para a criação de termos alternativos para o órgão sexual feminino contribuem para a aceitação social do conceito/objeto tabuizado, muito embora, na perspectiva hegemonizante de gênero adotada por uma sociedade de caráter patriarcal como a brasileira, tais conceitos/objetos/nomes são minimizados pela supremacia de ordem social, em que a figura masculina é proeminente.

Além disso, demonstram a atitude dos falantes de língua portuguesa do Brasil que, ao minimizar e contornar os aspectos tabuizados do léxico relativo ao órgão feminino, ratificam a proeminência da figura masculina, especialmente do órgão sexual masculino. É o caso, por exemplo, da nomenclatura que tipifica a vulva como um recipiente/extensão do pênis, expressa em metáforas linguísticas como "abocanhacaralho, abridor de caralho, abrigo-do-meu-pau, bababenga, babadeira do caralho, baba-pau, buraco de avestruz (esconde a cabeça), buraco de cobra, buraco de mandioca", dentre outros.

Tendo isso em vista, serão analisadas piadas (FREITAS, 2017) com designações alternativas jocosas para vulva, nas quais atuam o pensamento metafórico na ativação de mesclagem, sob a perspectiva da construção da identidade de gênero, a fim de ilustrar a depreciação do feminino, mesmo de forma velada.

\section{Metáfora Conceptual e Integração Conceptual}


A premissa básica da Teoria da Metáfora Conceptual fundamenta-se na ideia de que as metáforas são configuradas como forma de pensar, e não como uma ferramenta estilística da linguagem, conforme aventado na tradição literária. Nessa perspectiva, defende-se a ideia de que o pensamento atua fundamentalmente de forma metafórica, em que é possível compreender e experienciar uma coisa em termos da outra (LAKOFF; JOHNSON, 2002, p. 43).

Dessa forma, as metáforas conceptuais são concebidas como uma forma de raciocínio, como pode ser exemplificado pelo conceito de AMOR, estruturado pelo conceito de GUERRA, presente no uso linguístico ordinário em uma diversidade de expressões. A compreensão desses conceitos entrecruzados origina-se da interseção de dois domínios da experiência, um domínio-fonte (GUERRA - um domínio concreto e relativamente bem estruturado), e um domínio-alvo (AMOR - um domínio abstrato, compreendido por meio do domíniofonte).

Entre os desenvolvimentos subsequentes à visão de Lakoff e Johnson (1980) sobre o papel da metáfora no pensamento, destacam-se os estudos de Kövecses (2005, 2006, 2010), que evidenciam os aspectos culturais envolvido na ativação de metáforas conceptuais. Em consonância com Kövecses (2010, p. 324), tem-se, em algumas metáforas conceptuais, uma acepção mais ou menos normatizada, quando alocadas em um continuum ou uma escala de convencionalidade. Algumas delas são amplamente entrincheiradas e passam a ser conhecidas e utilizadas constantemente no discurso de uma comunidade.

É o caso da metáfora conceptual PÊNIS É OBJETO ERETO E RIJO, em que ocorre a correspondência sistemática entre os domínios conceptuais distintos. Essa metáfora consiste em uma especificação da metáfora CORPO HUMANO É OBJETO, que, por sua vez, é uma especificidade da metáfora PESSOA É OBJETO, cujos domínios fonte e alvo estão frequentemente presentes na ativação do pensamento metafórico convencional das interações cotidianas.
As experiências de ordem corpórea ou socioculturais suscitam a discussão em torno da universalidade e da variação na conceptualização de metáforas. Pode-se estabelecer que as experiências de ordem corpórea fundamentam as metáforas universais, e as experiências de ordem sociocultural motivam a variação no entendimento e na produção de metáforas.

A Mesclagem Conceptual, delineada inicialmente por Fauconnier e Turner (2002), constituise em um processo cognitivo básico e geral que lida diretamente com a forma como pensam os humanos. Apesar de parecer uma coisa simples, sua automaticidade ocorre de forma implícita, sem que o falante se dê conta do complexo de relações que ocorre no seu sistema conceptual. Trata-se de "uma operação mental que pode ser considerada a origem da nossa aptidão para inventar novos signos" (FERRARI, 2011, p. 120).

Nessa perspectiva, postula-se que a mesclagem conceptual, como uma faculdade de produção de imagens e de representação mental, é possível devido ao processamento de três operações cognitivas que mantêm uma relação mútua: (a) o reconhecimento de Identidades, nas quais figuram equivalências e oposições de determinadas estruturas, (b) a Integração, o novo sentido dado a essas identidades e (c) a Imaginação, sem a qual os eventos anteriores não conseguem se constituir, responsável pela ativação do cenário mental das crenças e dos eventos (em que se pode incluir a contrafactualidade).

Fauconnier e Turner (2002) esquematizaram uma rede de integração conceptual, em que é possível perceber a relação entre as diferentes esferas do conhecimento e a consequente integração dos conceitos na construção de significado. De acordo com Fauconnier e Turner (2002), em muitos casos, a nova significação procede de uma estrutura aparentemente indisponível na rede, mas que é ela a informação fundamental, na estrutura conceptual ou linguística, que funciona como input para o processo de conceptualização. Esse fato evidencia que, em alguns casos, a estruturação do significado não é 
passível de ser consistentemente explicada pela Teoria da Metáfora Conceptual com a projeção entre dois domínios. A integração conceptual origina algo maior do que a soma de duas partes (EVANS; GREEN, 2006, p.421).

Nessa perspectiva, a organização da rede é composta estruturalmente por pelo menos quatro espaços mentais em cuja composição mais simples existe um espaço genérico, dois inputs e um espaço mescla. Redes mais complexas podem ser ativadas por meio de mesclagens sucessivas encadeadas, em que o resultado de uma mescla pode configurar 0 input de nova integração conceptual, ou por meio de mais de dois inputs que projetam elementos no espaço mescla. Esse é o caso das mesclagens das piadas analisadas em Freitas (2017).

Dessa forma, à luz dos conceitos da metáfora conceptual e da rede de integração conceptual serão analisados os dados relativos à nomenclatura popular para vulva, bem como os valores e crenças relativos à representação e identidade de gênero feminino na sociedade.

\section{Conceptualização de designações para "vulva": tabu e preconceito}

O conceito de "tabu linguístico", tomado nesta análise, está em consonância com a formulação de Ullmann (1966, p. 245), segundo a qual uma das procedências dessa modalidade do tabu surge do senso de decência e decoro, cuja referência ao âmbito sexual e corporal - isto é, a nomes que referenciam determinadas partes e funções do corpo - é evitada. Conjectura-se que essa mudança lexical, embora suavize a palavra atingida por tabu e alivie o tensionamento provocado pela visão preconceituosa em relação à condição social feminina, também o reafirma por meio do emprego de recursos advindos do humor, tais como a jocosidade e o aspecto risível.

Dessa forma, a diligência na utilização de termos não propriamente restritos pelo tabu demonstra que a forma linguística presente nas designações metafóricas para vulva acoberta, em princípio, a restrição moral que subjaz à nomenclatura, mas não resguarda da influência dos valores e práticas sociais professados por uma sociedade de tradição patriarcal. Nesse sentido, esta seção dedica-se à observação da substituição vocabular de ordem moral e social dada à vulva, a qual é atenuada pelo aspecto chistoso das palavras, enfatizando-se as alterações ativadas por meio da metáfora e da integração conceptuais em um contexto de etimologia popular.

Os participantes, reunidos em grupos focais, foram submetidos ao método da leitura, que, conforme preconiza Sardinha (2007, p.145), "consiste em encontrar metáforas pela leitura de materiais escritos". O método em questão sugere que os dados a serem analisados sejam lidos mais de uma vez e, também, por outras pessoas, além do pesquisador, para que o produto final atinja um caráter mais imparcial e menos introspectivo. Dessa forma, foram aplicados testes semânticos junto a tais grupos para diminuir as possíveis chances de introspecção na análise dos dados.

Os textos selecionados para os testes foram elaborados por meio de uma seleção prévia de onze piadas via ferramenta Google. Para filtrar a busca, foram utilizadas as seguintes legendas, respectivamente:
(1) Piada [Nome dado ao Órgão]
(2) Piada de [Nome dado ao Órgão]
(3) Piada sobre [Nome dado ao Órgão]
(4) Piada [Nome dado ao Órgão] Conteúdo adulto

O perfil dos participantes era de estudantes do primeiro período do curso de Comunicação Social de uma universidade do Rio de Janeiro. Os estudantes foram informados que se tratava de análise para uma pesquisa sobre interpretação de piadas e que poderiam se sentir a vontade para escrever suas respectivas compreensões, sem qualquer preocupação com norma gramatical ou com a tipologia textual.

Três grupos foram formados - Grupo 1, Grupo 2 e Grupo 3 - com 14 informantes em cada, 
totalizando 42 interpretações fornecidas. Os testes interpretativos dos grupos 1 e 2 foram produzidos no mesmo formato, diferindo-se um do outro apenas na escolha das piadas. Nesses grupos, foram agrupadas cinco piadas de cunho sexual, duas delas sem qualquer alusão a algum órgão sexual, sendo, portanto, um texto distrator. Já no grupo 3, as cinco piadas elencadas contiveram uma possível menção a órgãos sexuais.

Com base no levantamento obtido, constatouse que a utilização de designações não anatômicas para os órgãos sexuais, de ordem metonímicometafórica, expressa uma regularidade de processos cognitivos na associação de objetos concretos aos órgãos sexuais, passando a um conceito abstrato. Em todas as respostas dos informantes, por exemplo, observou-se a ativação recorrente das relações vitais de REPRESENTAÇÃO (um objeto para representar o órgão sexual) e de ANALOGIA (a relação de semelhança entre o objeto e o órgão).

Outras relações vitais ativadas nas interpretações dos colaboradores, como as de CAUSA-EFEITO, DESANALOGIA, PAPEL-VALOR e PARTE-TODO, atuam majoritariamente no âmbito discursivo-pragmático, isto é, são relações vitais que auxiliam no contexto em que os nomes estão inseridos, sendo relações mais gerais as quais operam no entendimento da situação, e não estritamente na designação em si. Esse fato ratifica a ideia basilar, nos estudos em Linguística Cognitiva, de que os conceitos de base metafórica constituemse a partir das experiências contínuas do corpo no espaço físico ou sociocultural.

Dessa forma, observaram-se conceptualizações de natureza depreciativa e preconceituosa em relação à nomenclatura popular atribuída ao órgão sexual feminino. Verificou-se que os nomes dados ao pênis pautam-se em aspectos análogos a objetos eretos, tendo como base a condição aprumada do órgão em condição de excitação sexual. A metáfora conceptual geral PARTE DO CORPO HUMANO É OBJETO permite a metáfora específica PÊNIS É OBJETO ERETO E RIJO, em que o domínio-fonte de OBJETO ERETO E RIJO estrutura as expressões metafóricas em alusão ao PÊNIS, tais como "baguete, benga, bengala, berimbau, cano, espada, lenha, mastro, pau, terceiraperna, vara, viga etc.", observadas nas listas que impulsionaram o estudo inicial.

De igual modo, a experiência com alimentos de formato cilíndrico e estendido é o que fundamenta a designação do pênis nos termos "cacete, cenoura, espiga, linguiça, pepino, nabo, salame, salsicha", sendo, portanto, uma consequência da metáfora conceptual PÊNIS É ALIMENTO CILÍNDRICO E ERETO. Metonimicamente, identifica-se a condição ereta dos alimentos e vincula-se essa característica ao órgão sexual masculino que também se estrutura de forma aprumada em caso de funcionamento sexual.

Por outro lado, os dados fornecidos pelos informantes apontam para conceptualização do órgão sexual feminino em que se minimiza a condição social feminina, especialmente quando se observam, nas expressões metafóricas, analogias a objetos/animais que desqualifiquem essa parte do corpo feminino. Tais interpretações demonstraram uma incompatibilidade entre os nomes dados à genitália feminina e os significados atribuídos ao órgão sexual masculino, visto que a condição ereta do pênis reflete a virilidade da constituição do homem. Mesmo sabendo que o órgão sexual masculino não se mantém constantemente erguido, a analogia mantémse convencionalmente estável em diversas designações do pênis, o que indica que a conceptualização da figura do homem envolve aspectos internalizados socialmente que comumente o enaltecem e o sobrepõem na escala hierarquizada encontrada em sociedades de tradição patriarcal, como a brasileira.

Nesse contexto, observou-se, no emprego da nomenclatura para vulva, tendência oposta à estabilidade das analogias lisonjeiras para o pênis, já que há um constante cerceamento moral reduzindo o órgão feminino (i) a uma extensão do pênis, local onde o órgão sexual masculino pode adentrar; (ii) a animais, principalmente aqueles considerados repugnantes e/ou que exalam mau odor; e (iii) a 
objetos/matérias semelhantes a pelos em sua estrutura, tais como as plantas. Essas conceptualizações são ilustradas nas análises das piadas selecionadas.

\section{Piada 1}

Como é conhecida a profissão do médico ginecologista em Portugal?

Espião da casa do caralho.

http://www.osvigaristas.com.br/charadas/portug ues/

Último acesso em 03/05/2016

A piada de número 1 reflete o exposto em (i), em que $o$ ato sexual subjaz ao entendimento da piada a partir da metáfora do pensamento VULVA É RECEPTÁCULO DO PÊNIS, a qual estrutura as metáforas linguísticas em que a vulva é vista em termos de objeto recipiente (nesse caso, do pênis). A base estável do conhecimento a partir da qual essa ideia se desenvolve está ligada ao esquema imagético de CONTÊINER, que origina tipos significados mais abstratos. Por conta dessa experiência sensório-motora, existem nomes para a vulva como "a casa de todos os pintos, abocanha-caralho, agasalhador de croquete, área vip, banco de esperma, caixa dos prazeres, túnel cheiroso" entre outras. Todas essas conceptualizações de vulva podem ser consideradas especificações da metáfora convencional CORPO É OBJETO (CONTÊINER).

Além disso, infere-se que o humor surge no acionamento da ideia de que o ginecologista não é propriamente a pessoa que tem acesso consentido à vulva cotidianamente. Ao contrário disso, seria um espião, porque "bisbilhota" o que "não lhe pertence", sugerindo um dono para a genitália feminina, que, nesse caso, é o pênis. Por meio da REPRESENTAÇÃO, a vulva é retratada como a "casa do caralho" ou "a casa do pênis, conferindo-lhe o significado de "estância do pênis": local onde o pênis reside. Em conformidade com os dados obtidos pelos informantes, a Figura (1) ilustra a representação da rede para conceptualização da piada 1 .

Figura 1 - Rede de Integração Conceptual da Piada 1 Fonte: Freitas (2017)

\section{Piada 2}

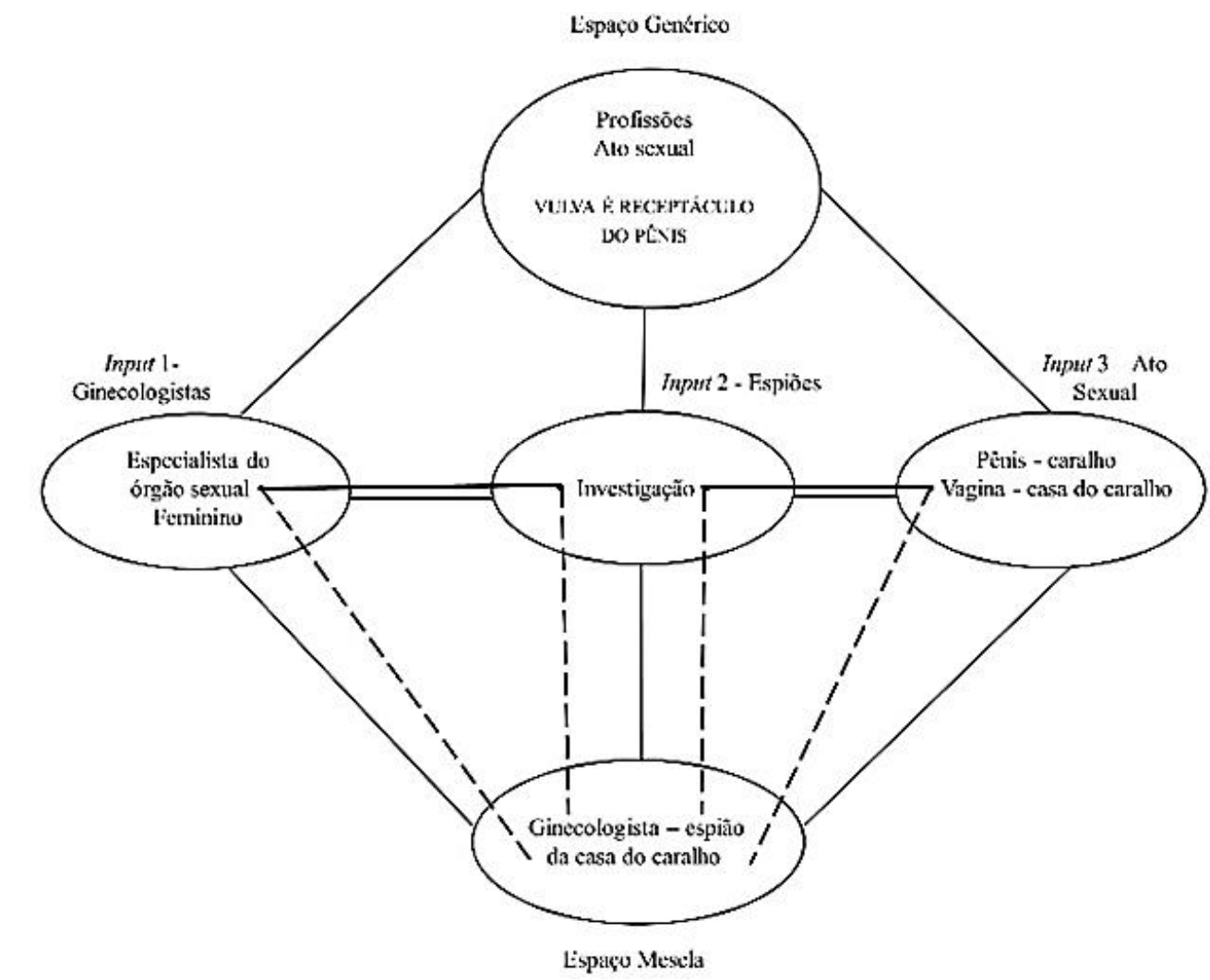


Um casal namorava na sala da casa, enquanto a mãe da moça, na cozinha, preparava uns croquetes para eles. Tão logo terminou de fritálos, os chamou para experimentar.

O rapaz logo que deu o primeiro bocado, já foi logo elogiando:

- Hum, que delícia! É de bacalhau!

Ao que a mãe da moça logo censurou:

- Que bacalhau, que nada rapaz. É de carne. Vá lavar sua mão!

http://www.sergeicartoons. com/croquete_cheiroso.ht $m$

Último acesso em 03/05/2016

A piada de número 2 reflete o exposto em (ii) em que, por REPRESENTAÇÃO, o conceito de bacalhau, em decorrência de seu odor, pode ser compreendido como o órgão sexual feminino e, também, por ANALOGIA, uma vez que as contrapartes experienciadas dos domínios do cheiro do animal e do cheiro da vulva se integram. Essa visão desfavorável em que a vulva é compreendida norteiase pela ideia implícita, amplamente difundida na comunidade linguística, de que o órgão sexual feminino pode ser conceptualizado em termos de animais.

Trata-se de um conceito convencionalizado socialmente e estruturado pela metáfora geral PARTE DO CORPO HUMANO É ANIMAL, a qual particulariza a metáfora conceptual VULVA É ANIMAL (FÉTIDO) e, consequentemente, viabiliza metáforas linguísticas como "bacalhau com natas, bacalhau mijado, bacalhoada, bacalhoeta, bacalhuda, cheiro de bacalhau, nugget de peixe" entre outras referências metafóricas à vulva. A rede de integração conceptual, apresentada na Figura (2), demonstra o trajeto mental fornecido pelos informantes para a conceptualização do sentido da piada 2 .

Figura 2 - Rede de Integração Conceptual da Piada 2 
As experiências com formato de plantas fundamentam muitas das metáforas linguísticas que designam a vulva, sendo algumas dessas nomeações "floresta das cobras, floresta negra, buraco no meio da floresta, planta carnívora, mato, Mato Grosso do Sul, África (mata-fechada ou alusão ao negrume do cabelo pixaim), caiçara (no sentido de mata espessa onde o caçador se embosca), gruta da mata funda" entre outras. Tendo isso em vista, apresenta-se, na Figura (3), a rede de integração para a conceptualização da piada 3 , conforme evidenciado nas interpretações dos informantes.

Figura 4 - Rede de Integração Conceptual da Piada 3

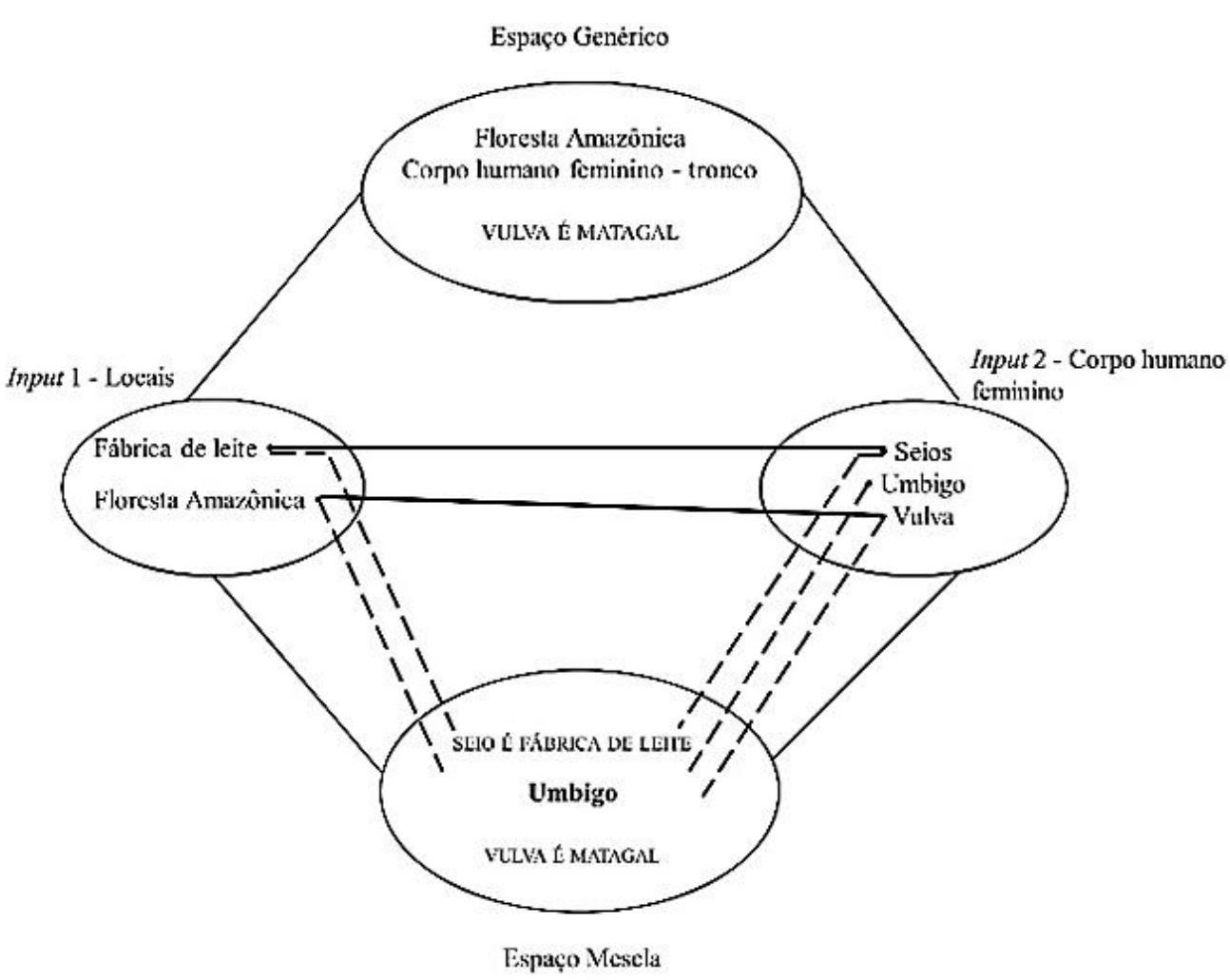

Fonte: Freitas (2017)

\section{Considerações finais}

Embora embrionários, devido ao número de ocorrências analisadas, os dados coletados apontam aspectos relevantes acerca da discussão em torno da construção de gênero feminino, produzida sob a perspectiva de uma sociedade de caráter patriarcal como a sociedade brasileira. O preconceito arraigado socialmente em relação à condição da mulher pode ser visto de forma depreciada, metonimicamente, nas designações populares e metafóricas ao seu órgão sexual, perpetuando a ideia de elevação da efígie masculina.

Nesse certame, em que a figura masculina é proeminente, demonstra-se a conduta preconceituosa dos indivíduos que, ao minimizar e contornar os aspectos tabuizados do léxico relativo ao órgão feminino, acabam por ratificar a superioridade da figura masculina, especialmente tratando-se do órgão sexual masculino, uma vez que a figura da mulher é depreciada na nomeação de seu órgão sexual. A expressão "é pica" com sentido de algo bom, frequentemente verbalizada por homens e mulheres indistintamente, ilustra a tendência de valorização do masculino face ao feminino em nossa sociedade.

Em vista do que foi produzido, constatou-se que não se pode negar a criatividade em integrar conceitos de forma jocosa para se contornar objetos/palavras atingidos por tabu. Os mecanismos da metáfora e da integração conceptuais desempenham papel crucial na elucidação desse processo de criação de novos significados/novas designações. Porém, é possível que a construção de significação em torno de aspectos ligados ao gênero feminino, tais como demonstrados neste estudo, corrobore as atitudes de discriminação e intolerância às quais a mulher é submetida socialmente, sendo, portanto, demonstrações de violência veladas.

\section{Referências}

FAUCONNIER, G.; TURNER, M. The way we think: conceptual blending and the mind's hidden complexities. New York: Basis Books, 2002. 
FERRARI, L. Introdução à linguística cognitiva. São Paulo: Contexto, 2011.

FREITAS, P. O. de. Mesclagem conceptual na construção de sentido em piadas com nomes de órgãos sexuais. 2017. 122 f. Dissertação (Mestrado em Linguísticas) - Instituto de Letras, Universidade do Estado do Rio de Janeiro, Rio de Janeiro, 2017.

KÖVECSES, Z. Metaphor in Culture: Universality and Variation. New York: Cambridge University Press, 2005.

Language, Mind and Culture: a practical introduction. New York: Oxford University Press, 2006.

Metaphor: a practical introduction. New York: Oxford University Press, 2010.

LAKOFF, G.; JOHNSON, M.. Metáforas da vida cotidiana [coordenação de tradução Mara Sophia Zanotto]. Campinas-SP: Mercado de Letras; São Paulo: EDUC, [1980] 2002.

SARDINHA, Tony Beber. Metáforas. São Paulo: Parábola, 2007.

\section{COMO CITAR ESSE ARTIGO}

FREITAS, Patrícia Oliveira de; BERNARDO, Sandra Pereira; CAVALCANTI, Fernanda Carneiro. Conceptualização de órgãos sexuais e identidade de gêneros: tabu e preconceito. Signo, Santa Cruz do Sul, v. 42, n. 75, dez. 2017. ISSN 1982-2014. Disponível em: <https://online.unisc.br/seer/index.php/signo/article/view/9835>. Acesso em: doi: http://dx.doi.org/10.17058/signo.v42i75.9835. 